\title{
Ginsenoside Rg3 inhibits the migration and invasion of liver cancer cells by increasing the protein expression of ARHGAP9
}

\author{
MENG-YAO SUN ${ }^{1}$, YA-NAN SONG ${ }^{2}$, MIAO ZHANG ${ }^{2}$, CHUN-YAN ZHANG $^{2}$, \\ LI-JUN ZHANG ${ }^{2}$ and HONG ZHANG $^{1,2}$ \\ ${ }^{1}$ Department of Pharmaceutical Botany, School of Pharmacy, Second Military Medical University, Shanghai 200433; \\ ${ }^{2}$ Central Laboratory, Seventh People's Hospital of Shanghai University of Traditional Chinese Medicine, \\ Shanghai 200137, P.R. China
}

Received February 26, 2017; Accepted August 10, 2018

DOI: $10.3892 / \mathrm{ol} .2018 .9701$

\begin{abstract}
Ginsenoside Rg3, a naturally occurring phytochemical, serves an important role in the prevention and treatment of cancer. In the present study, with the aim to reveal the molecular mechanism of $\operatorname{Rg} 3$ in liver cancer cell metastasis, the anti-migration and anti-invasion effects of $\operatorname{Rg} 3$ on liver cancer cells were investigated. It was demonstrated that $\mathrm{Rg} 3$ caused marked inhibition of cell migration and invasion of human liver cancer cells, HepG2 and MHCC-97L, in vitro, and the growth of HepG2 and MHCC-97L tumors in BABL/c nude mice. The protein expression of Rho GTPase activating protein 9 (ARHGAP9) was increased both in HepG2 and MHCC-97L cells. Following ARHGAP9 knockdown, the results of Transwell and tumorigenesis assays revealed that the anti-migration, anti-invasion and anti-tumor growth effects of Rg3 were impaired significantly. The increased expression of ARHGAP9 protein induced by Rg3 was remarkably suppressed. All results suggested that ARHGAP9 protein may be a vital regulator in the anti-metastatic role of $\mathrm{Rg} 3$. To the
\end{abstract}

Correspondence to: Professor Hong Zhang, Department of Pharmaceutical Botany, School of Pharmacy, Second Military Medical University, 325 Guohe Road, Yangpu, Shanghai 200433, P.R. China

E-mail: hqzhang51@126.com

Dr Li-Jun Zhang, Central Laboratory, Seventh People's Hospital of Shanghai University of Traditional Chinese Medicine, 358 Datong Road, Shanghai 200137, P.R. China

E-mail: zhanglijun0407@163.com

Abbreviations: CCK-8, Counting kit-8; DLC, Deleted in liver cancer; DMEM, Dulbecco's modified Eagle medium; DMSO, dimethyl sulfoxide; FBS, fetal bovine serum; HCC, hepatocellular carcinoma; MAPK, Mitogen-activated protein kinases; MMPs, Matrix metalloproteinases; PA, plasminogen activator; Rho GAPases, Rho GTPase activation proteins; VEGF, vascular endothelial growth factor.

Key words: ginsenoside $\mathrm{Rg} 3$, anti-migration, anti-invasion, Rho GTPase activating protein 9, hepatocellular carcinoma best of our knowledge, the present study is the first to report that $\mathrm{Rg} 3$ effectively suppressed the migration and invasion of liver cancer cells by upregulating the protein expression of ARHGAP9, indicating a novel natural therapeutic agent and a therapeutic target for the treatment of liver cancer.

\section{Introduction}

Primary liver cancer is one of the most aggressive types of neoplasm, characterized by high morbidity and mortality rates (1-3). Although the prevalence of liver cancer is highest in the Far East and Sub-Saharan Africa, its incidence has increased in Western countries (4), and it is predicted that the incidence of liver cancer in the United States will continue to increase in the next two decades (5). At present, surgical intervention (resection or transplant) is the first line therapeutic method for cases of primary liver cancer at an early stage. However, systemic metastasis and postsurgical recurrence negatively affect the prognosis of patients with liver cancer (2). Unfortunately, the majority of liver cancer cases are diagnosed at at an advanced stage, by which metastasis has occurred and no curative treatment is available (6). Therefore, metastasis is the leading factor that results in the high mortality rate and poor 5-year survival rate $(<9 \%)$ in patients with liver cancer (7).

Tumor metastasis is a highly integrated, multistep process which is closely associated with a series of molecules, including Rho GTPase activation proteins (Rho GAPases), matrix metalloproteinases (MMPs), vascular endothelial growth factor (VEGF), plasminogen activator (PA) etc (8-13). Rho GTPases belong to the Ras super-family, including RhoA, RhoB and RhoC (14). Previous studies have demonstrated that Rho GTPases serve a vital role in tumor progression and metastasis by regulating cell proliferation, the actin cytoskeleton and cell adhesion (15). Furthermore, Rho GTPases often appear to be elevated or to have their activity increased in several human tumors by changing three major classes of regulators including Rho GAPs, GEFs and GDIs (16). Notably, RhoA was frequently found to be over-expressed in liver cancer and which is associated with tumor metastasis, a lower survival rate and a higher chance of tumor recurrence (17). As important negative regulators of Rho signaling, numerous RhoGAPs have been demonstrated to be downregulated in liver cancer, including p190RhoGAP, Deleted in liver cancer (DLC) 
family and Rho GTPase activating protein 9 (ARHGAP) (18), which indicated the association of RhoGAPs and liver cancer. RhoGAPs are emerging as a novel cancer-related biomarker in recent years (19). ARHGAP9 is a member of the RhoGAP family, and also named RhoGAP9 (20). It has been demonstrated that ARHGAP9 inhibits Erk2 and p38 $\alpha$ activation in Swiss 3 T3 fibroblasts by binding to mitogen-activated protein kinases (MAPKs), which serve pivotal roles in cell proliferation and metastasis (21). ARHGAP9 reduced the adhesion of hematopoietic cells to the extracellular matrix and the migration of vero cells (22). Studies using bioinformatics determined that ARHGAP9 is a cancer-associated gene (23), however, no studies have reported an association between ARHGAP9 and cancer.

Ginsenoside $\mathrm{Rg} 3$, one of the bioactive ginsenosides extracted from Panax ginseng C.A. Meyer, displays significant anti-metastasis effects in numerous types of cancer models. For example, Rg3 was reported to effectively inhibit lung cancer metastasis by suppressing epithelial-mesenchymal transition (24,25). Rg3-induced downregulation of MMPs has been demonstrated to be associated with the decreased invasive capacity of ovarian cancer SKov3 cells and colon cancer SW480 cells $(26,27) . \operatorname{Rg} 3$ was also demonstrated to inhibit the migration of Eca-109 and 786-0 cells through suppressing VEGF expression (28). The aim of the present study was to investigate the potential functions and molecular mechanisms of $\mathrm{Rg} 3$ against liver cancer cell metastasis.

\section{Materials and methods}

Reagents. 20(R)-ginsenoside Rg3 (98\% pure, Fig. 1A) was purchased from the Nanjing Zelang Biological Technology Company (Jiangsu, China). It was dissolved in dimethyl sulfoxide (DMSO) and stored at $-20^{\circ} \mathrm{C}$. Anti-ARHGAP9 was purchased from Abcam (Cambridge, UK; cat. no. Ab101361) and anti-GAPDH was purchased from Cell Signalling Technology, Inc. (Danvers, MA, USA; cat. no. 5174).

Cell culture. The human liver cancer cell lines, HepG2, SK-Hep1, MHCC-97L, MHCC-97H, SMMC-7721and BEL-7404, were provided by the Shanghai Cell Bank, Chinese Academy of Sciences (Shanghai, China) (http://www.cellbank. org.cn/index.asp). HepG2 is a human hepatoblastoma cell line, commonly misidentified as hepatocellular carcinoma (29). SK-Hep1 and the remaining cell lines were cultured in RPMI-1640 medium and Dulbecco's modified Eagle's medium (DMEM), respectively, which were supplemented with $10 \%$ fetal bovine serum (FBS),100 units/ml penicillin and $100 \mu \mathrm{g} / \mathrm{ml}$ streptomycin at $37^{\circ} \mathrm{C}$ in $5 \% \mathrm{CO}_{2}$.

Cell viability analysis. Cells were seeded in 96-well plates at a density of 2,000 cells per well, incubated overnight, and treated with different concentrations of $\operatorname{Rg} 3(0,1.25,2.5,5,10$, 20,40 and $60 \mu \mathrm{g} / \mathrm{ml}$ ) for 12, 24 and $48 \mathrm{~h}$. The cell proliferation was quantitated using Cell Counting kit-8 (CCK-8; Dojindo Laboratories, Japan), according to the manufacturer's recommendations. Control cells were treated with culture media containing $0.15 \%$ (v/v) DMSO.

Reverse transcription-quantitative polymerase chain reaction (RT-qPCR) analysis. Total RNA was extracted from the cells with TRIzol (Invitrogen; Thermo Fisher Scientific, Inc., Waltham, MA, USA) and reverse transcribed to cDNA with oligo(dT) primers (Fermentas; cat. no. K1622; Thermo Fisher Scientific, Inc.), according to the manufacturer's protocol. SYBR Green-based RT-qPCR (Maxima SYBR-Green/ROX qPCR Master Mix 2X; cat. no. K0223; Thermo Fisher Scientific, Inc.) was performed to examine the relative ARHGAP9 mRNA level, which was normalized to GAPDH. The primer sequences were as follows: ARHGAP9 forward, 5'-GAAGAGACCGCC CTTACAAAGC-3' and reverse, 5'-GCTCACCCGATAAAT GCCATCC-3'; GAPDH forward, 5'-CACCCACTCCTCCAC CTTTG-3' and reverse, 5'-CCACCACCCTGTTGCTGTAG-3'.

RNA interference. A total of 3 small interfering RNAs (siRNAs) targeting ARHGAP9 mRNA were synthesized: siRNA1, 5'-GACGCUGCUUCUACAUAAA-3'; siRNA2, 5'-GUGGUG UUAACGGGUAACA-3', and siRNA3, 5'-GCGUGCGCA ACAAACUAAA-3', and a control siRNA (siNC). The siRNAs were transiently transfected into MHCC-97L cells using Lipofectamine 2000 (Invitrogen; Thermo Fisher Scientific, Inc.), according to the manufacturer's instructions. The most effective siRNAs were selected according to the results of RT-qPCR and western blotting after $48 \mathrm{~h}$. Then MHCC-97L cells were transfected with siRNA3 and a 24-h Rg3 treatment followed after $24 \mathrm{~h}$. The effect of ARHGAP9 silencing on the anti-invasive properties of $\operatorname{Rg} 3$ was assessed by Transwell assay.

Western blot analysis. The protein concentration was analyzed by Bicinchoninic Acid Protein Assay Reagent (Sangon Biotech Co., Shanghai, China), according to the manufacturer's protocols. Soluble lysates containing $20 \mu \mathrm{g}$ proteins per sample were separated via SDS-PAGE on a $10 \%$ gel and subsequently transferred onto polyvinylidene fluoride membranes. Subsequent to blocking with $5 \%$ bovine serum albumin at $4{ }^{\circ} \mathrm{C}$ for $1 \mathrm{~h}$, membranes were incubated with primary antibodies anti-ARHGAP9 (dilution, 1:1,000; cat. no. Ab101361; Abcam) and anti-GAPDH (dilution, 1:1,500; cat. no. 5174; Cell Signalling Technology) at $4^{\circ} \mathrm{C}$ overnight. Following washing with TBS Tween-20, the membranes were incubated with secondary antibody horse-radish peroxidase-labeled goat anti-rabbit IgG (dilution, 1:1,000; cat. no. A0208; Beyotime Institute of Biotechnology, Shanghai, China) at room temperature for $1 \mathrm{~h}$. The membrane signals were detected using an Enhanced Chemiluminescent Western Blotting Detection System (Bio-Rad Laboratories, Hercules, CA, USA), according to the manufacturer's protocols. Quantification of protein expression was performed by Image J 1.6 software (National Institutes of Health, Bethesda, MD, USA).

Cell migration and invasion assays. Cell migration was examined using a Transwell migration assay. Cells were suspended in serum-free DMEM medium and $5 \times 10^{5}$ cells $/ \mathrm{ml}$ were seeded into the upper chamber, with $8-\mu \mathrm{m}$ pores (Corning Incorporated, Corning, NY, USA) while DMEM with $10 \%$ FBS was added to the lower chamber. After a 24-h incubation, non-migrated cells were removed with cotton swabs, and microscopic images of the migrated cells were captured in 5 random random fields (magnification, $\mathrm{x} 200$ ). The migration capability of the cells was measured by counting the number of cells present. The data are expressed as the mean number of cells/field \pm standard deviation. 
A

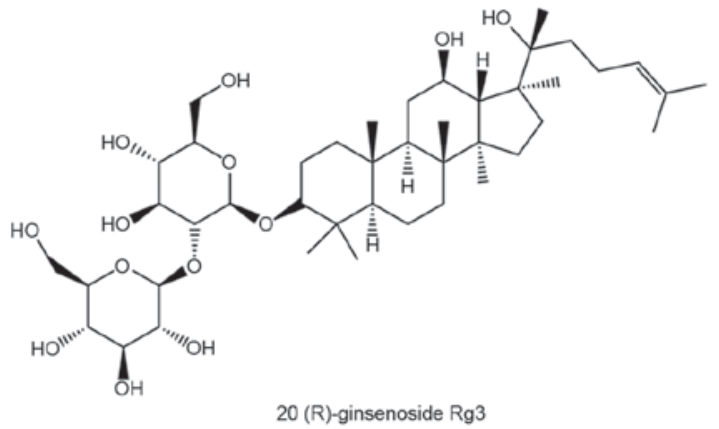

B

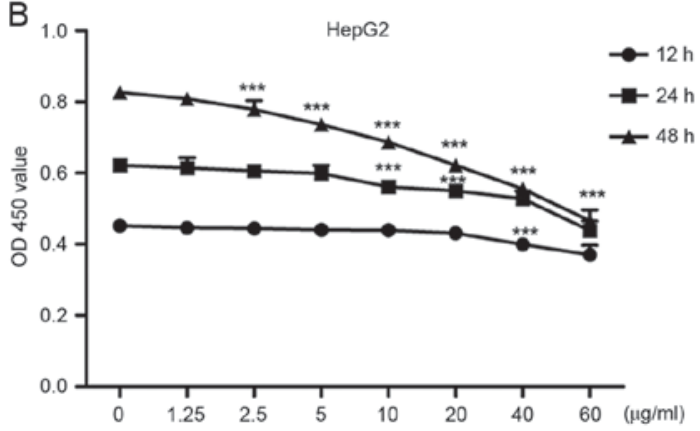

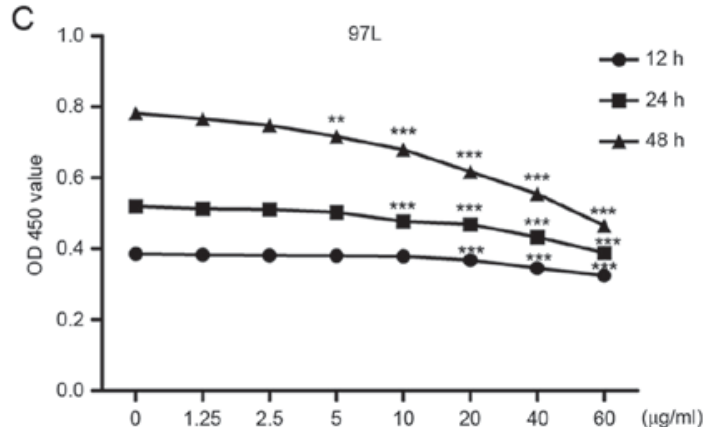

Figure 1. The anti-proliferative effects of Rg3 on HepG2 and MHCC-97L cells. (A) The chemical structure of Rg3. (B) Effects of Rg3 on HepG2 cell viability. (C) Effects of Rg3 on MHCC-97L cell viability. Cells were treated with the indicated concentrations of Rg 3 for 12 or 24 h, and cell viability was determined by Cell Counting kit- 8 assay. All data are presented as the mean \pm standard deviation from three independent experiments $(\mathrm{n}=6) .{ }^{* *} \mathrm{P}<0.01,{ }^{* * * *} \mathrm{P}<0.001 \mathrm{vs} .0 \mu \mathrm{g} / \mathrm{ml}$.

For the invasion assay, $1 \mathrm{mg} / \mathrm{ml}$ Matrigel (BD Biosciences, Franklin Lakes, NJ, USA) was pre-coated onto the Transwell membrane, and the remaining steps were performed as per the migration assay.

In vivo tumorigenesis. Male 5-week old $\mathrm{BALB} / \mathrm{c}$ nude mice were purchased from SLAC Laboratory Animal Center (Shanghai, China), anesthetized and $5 \times 106$ HepG 2 cells or $5 \times 10^{6}$ MHCC-97L cells in $200 \mu$ PBS were injected subcutaneously into the right forelimb. $\operatorname{Rg} 3$ was administrated to the rats by oral gavage, and distilled water with $0.5 \% \mathrm{CMC}-\mathrm{Na}$ was used as a control. After 21 days the nude mice were sacrificed by cervical dislocation and the tumor tissues were excised and weighed. The experiments were approved by the Experimental Animal Ethical Committee of Seventh People's Hospital of Shanghai University of Traditional Chinese Medicine (Shanghai, China).

Statistical analysis. In vivo data are presented as the mean \pm standard error of the mean and in vitro data are presented as the mean \pm standard deviation. Student's t-test was used to compare the difference between the two groups. One-way analysis of variance followed by Dunnet's test was performed for comparisons between multiple groups. $\mathrm{P}<0.05$ was considered to indicate a statistically significant difference.

\section{Results}

The anti-proliferative effects of $\mathrm{Rg} 3$. The effects of $\mathrm{Rg} 3$ on liver cancer cell viability were investigated by CCK-8 assay. As demonstrated by Fig. 1B and C, Rg3 exhibited a dose- and time-dependent anti-proliferative effect on HepG2 and MHCC-97L cells. Cell viability decreased with longer duration or/and increased concentration of $\mathrm{Rg} 3$. There was no noticeable influence on cell viability with $\mathrm{Rg} 3$ at low concentrations $(1.25,2.5$ or $5 \mu \mathrm{g} / \mathrm{ml})$ for 12 or $24 \mathrm{~h}$.

The anti-migration and anti-invasion effects of Rg3. To evaluate the effect of $\mathrm{Rg} 3$ on the metastasis of liver cancer cells, Transwell assays of HepG2 and MHCC-97L cells were performed. After a 24-h incubation of $\mathrm{Rg} 3$ at concentrations of $1.25,2.5$ and $5 \mu \mathrm{g} / \mathrm{ml}$, it was demonstrated that the number of migratory and invasive HepG2 and 97L cells was significantly reduced compared with those of the control group (Fig. 2).

Rg3 suppresses tumor growth of liver cancer cells in nude mice. BALB/c nude mice administered with $\operatorname{Rg} 3$ for 21 days exhibited significant decrease in tumor size compared with the control mice (Fig. 3A and B). The weight of the tumors decreased with increasing $\operatorname{Rg} 3$ dose.

The increased expression of ARHGAP9 induced by Rg3. ARHGAP9, as a member of the RhoGAP family, has been reported to be associated with cell migration in previous studies (20-22). Bioinformatics investigation revealed that ARHGAP9 is a cancer-associated gene (23). Whether the expression of ARHGAP9 was regulated by $\mathrm{Rg} 3$ in liver cancer cells was investigated. Western blot analysis demonstrated that the expression of ARHGAP9 protein were significantly increased in a dose-dependent manner following treatment of HepG2 and MHCC-97L cells with Rg3 (Fig. 4A and B).

Knockdown of ARHGAP9 attenuates the anti-metastatic effect of $R g 3 . \operatorname{Rg} 3$ inhibits the migration and invasion of liver cancer cells, as well as increases the expression of ARHGAP9. 

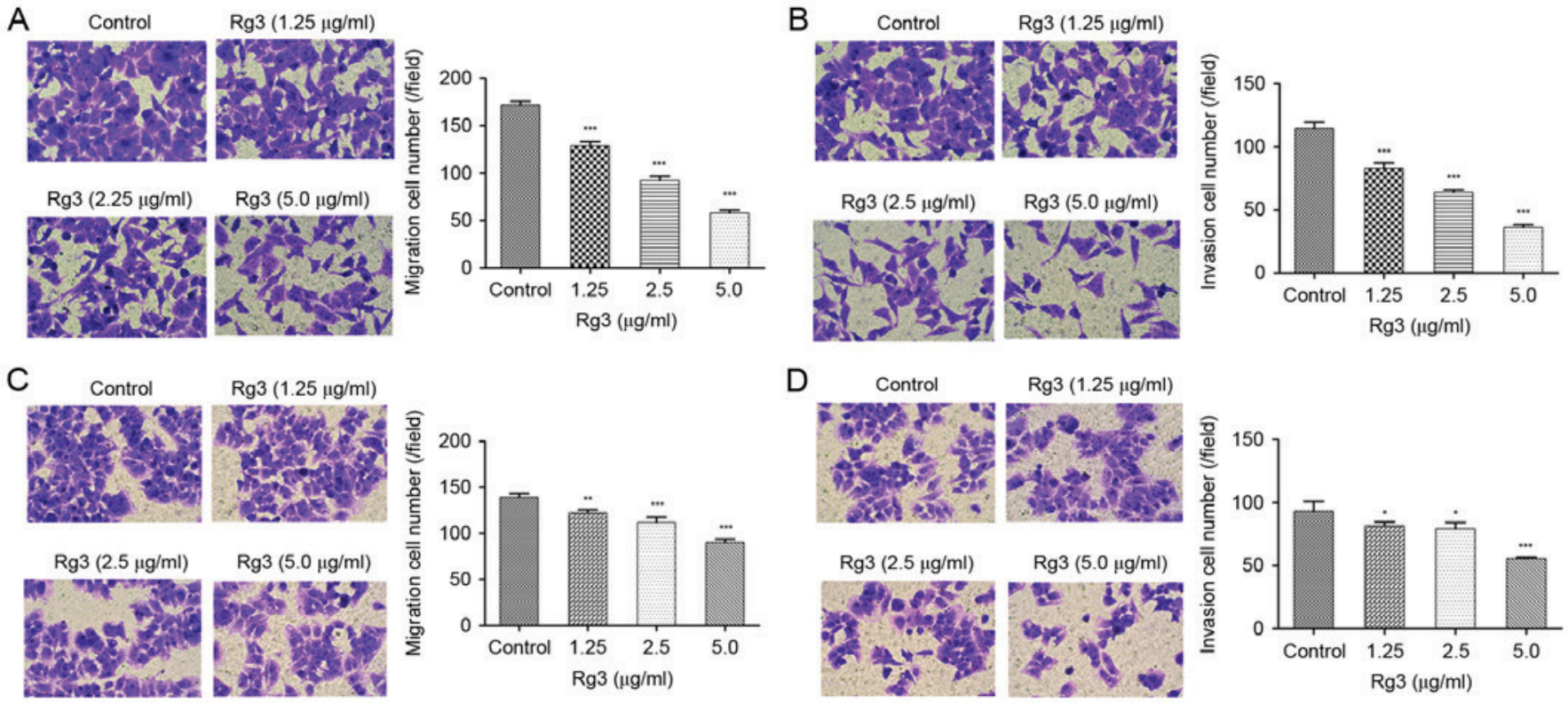

Figure 2. The anti-migration and anti-invasion effects of Rg3 on HepG2 and MHCC-97L cells. (A) The effect of Rg3 on HepG2 cell migration. (B) The effect of Rg3 on HepG2 cell invasion. (C) The effect of Rg3 on MHCC-97L cell migration. (D) The effect of Rg3 on MHCC-97L cell invasion. Cells were cultured without (control) and with $1.25,2.5$ and $5 \mu \mathrm{g} / \mathrm{ml} \mathrm{Rg} 3$ for $24 \mathrm{~h}$, and migration and invasion were measured by Transwell assay. ${ }^{*} \mathrm{P}<0.05,{ }^{* *} \mathrm{P}<0.01$, ${ }^{* * * *} \mathrm{P}<0.001$ vs. control.
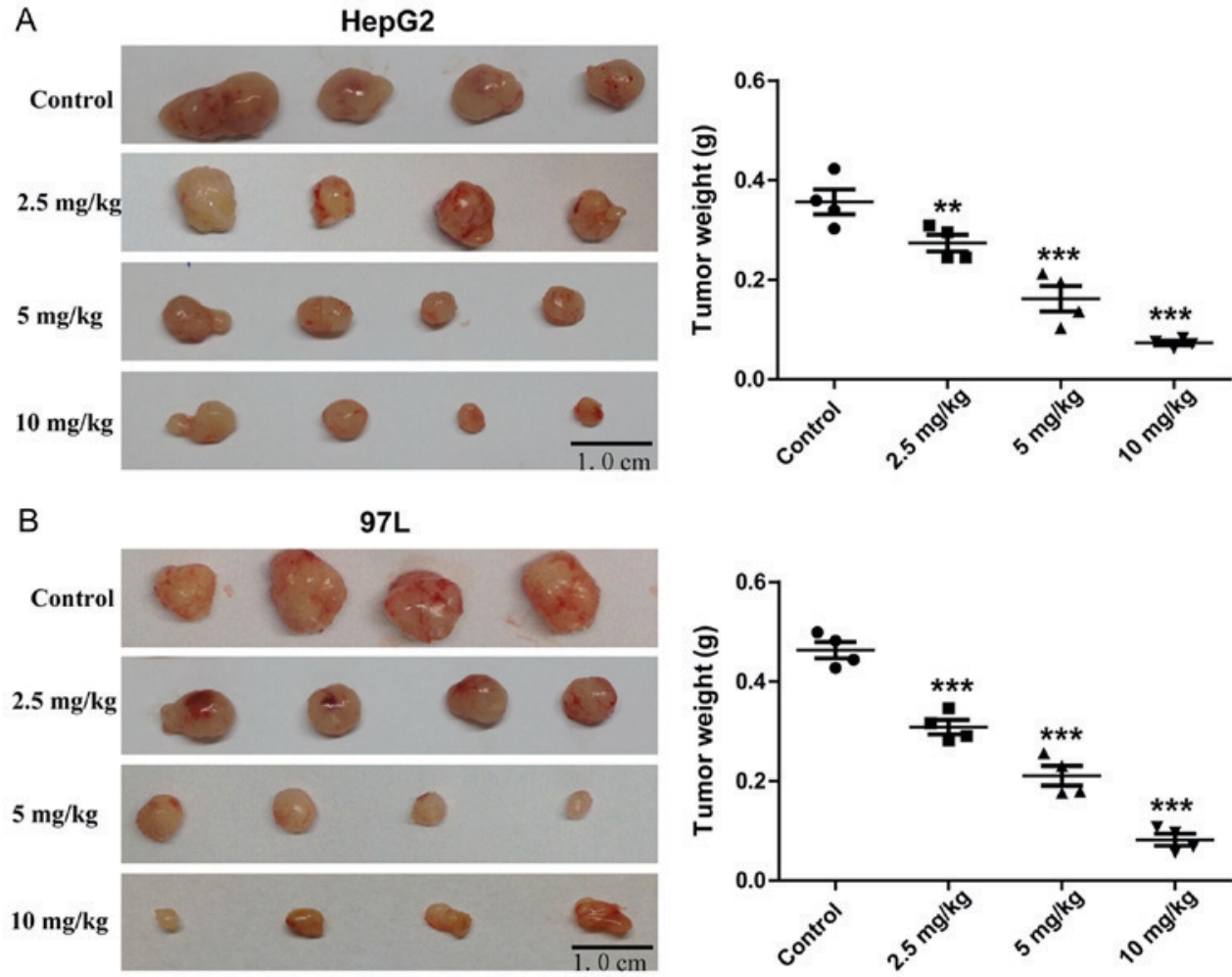

Figure 3. Rg3 suppresses tumor growth of HepG2 and MHCC-97L cells in nude mice. (A) The photographs and weights of HepG2 tumors (scale bars, $1 \mathrm{~cm}$.). (B) The photographs and weights of MHCC-97L tumors. HepG2 and MHCC-97L cells were subcutaneously injected in the right forelimb of nude mice. 2.5, 5 and $10 \mathrm{mg} / \mathrm{kg} \mathrm{Rg} 3$ was administrated to the nude mice by gavage, and distilled water was used as a vehicle control. After 21 days the nude mice were killed and tumor tissues were excised and weighed (scale bars, $1 \mathrm{~cm})(\mathrm{n}=4){ }^{* *} \mathrm{P}<0.01,{ }^{* * *} \mathrm{P}<0.001$ vs. control.

Whether the anti-migration and anti-invasion effects of $\operatorname{Rg} 3$ were mediated by ARHGAP9 was explored.

To better understand the role of ARHGAP9 in anti-metastatic behavior of $\mathrm{Rg} 3$ in $\mathrm{HCC}$ cells, the expression levels of ARHGAP9 were measured in six human liver cancer cell lines (HepG2, SK-Hep1, MHCC-97L, MHCC-97H, SMMC-7721 and BEL-7404). The expression of ARHGAP9 in the MHCC-97L cell line was higher than that in the other cell lines (Fig. 5A and B). siRNAs (siRNA1, siRNA2 and siRNA3) or control siRNA (siNC) were transfected into 
A
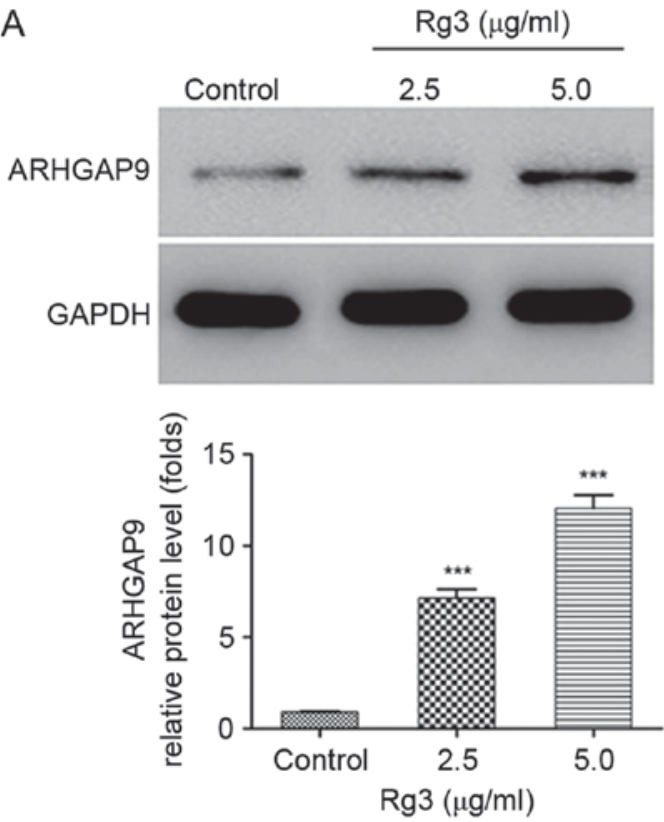

B
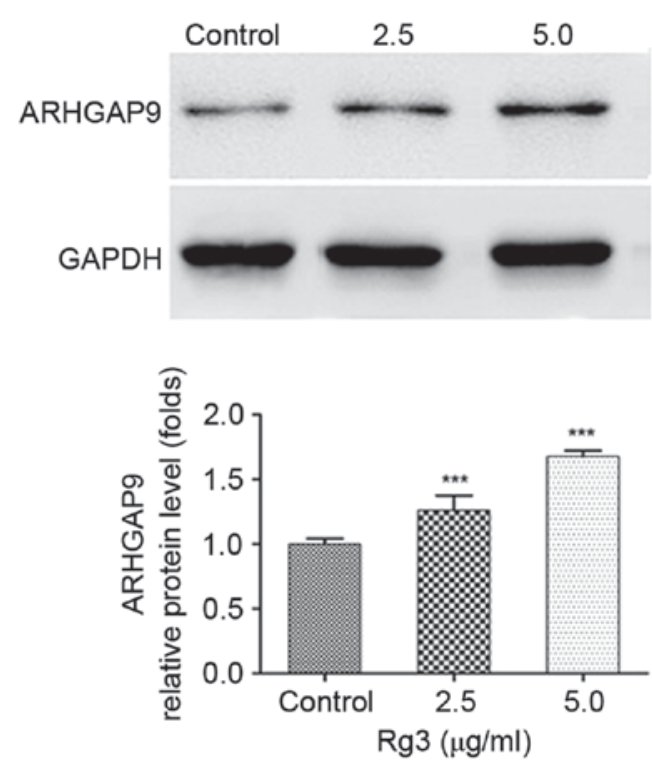

Figure 4. Effects of Rg3 on ARHGAP9 expression in HepG2 and MHCC-97L cells. Cells were treated with the indicated concentrations of Rg3 for $24 \mathrm{~h}$. (A) Representative images of three independent western blots $(n=3)$ and quantification of the levels of ARHGAP9 protein expression in HepG2 cells (B) Representative images of three independent western blots $(\mathrm{n}=3)$ and quantification of the levels of ARHGAP9 protein expression in MHCC-97L cells. All the data represents the mean \pm standard deviation. ${ }^{* * * *} \mathrm{P}<0.001$ vs. control.

A

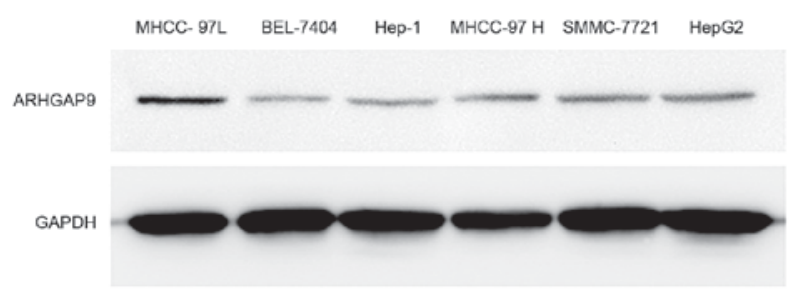

B

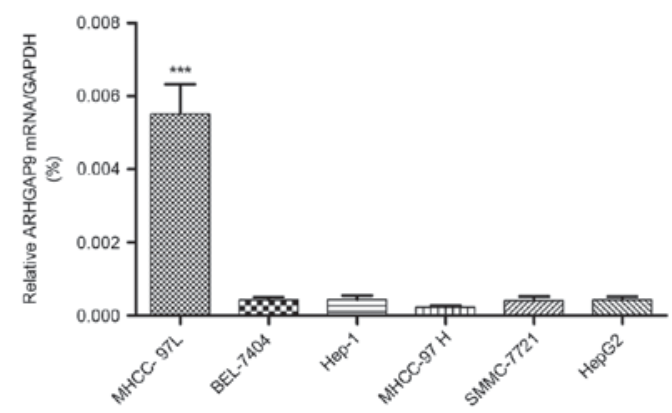

D

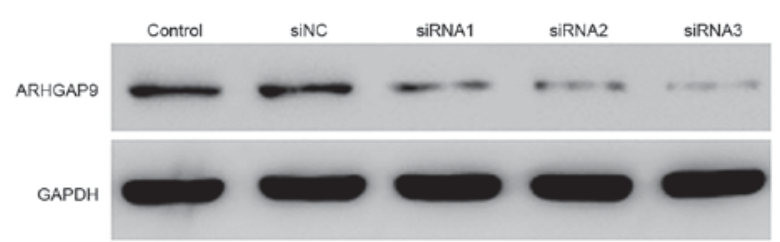

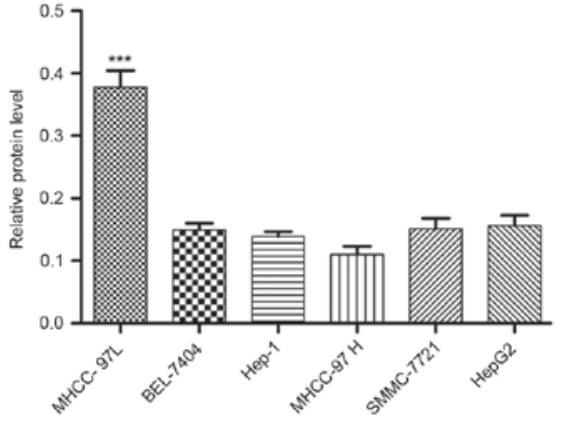

C
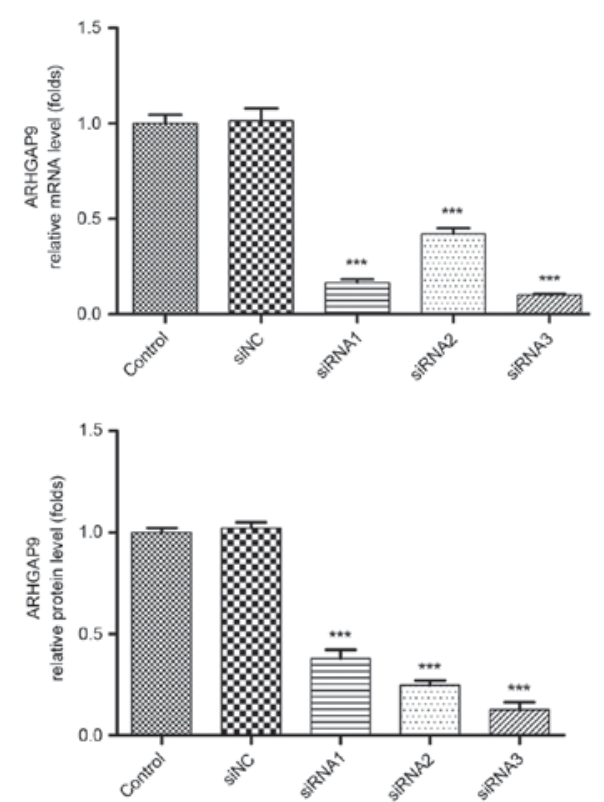

Figure 5. Knockdown of ARHGAP9 by siRNA transfection. ARHGAP9 protein expression was analyzed by (A) western blotting and (B) reverse transcription-quantitative polymerase chain reaction $\left({ }^{* * * *} \mathrm{P}<0.001\right.$, ARHGAP9 in MHCC-97L vs. other groups ). The efficiency of ARHGAP9 silencing in

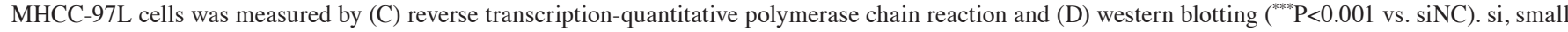
interfering RNA; NC, negative control. 
A

Rg3 (0)

Rg3 (2.5)

Rg3 (5.0)

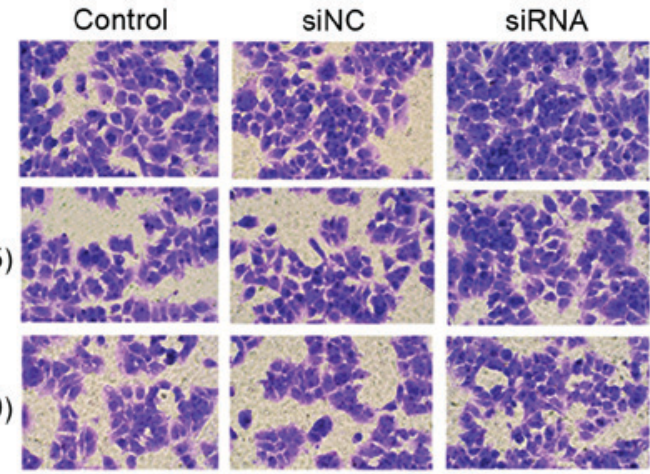

B

Rg3 (0)

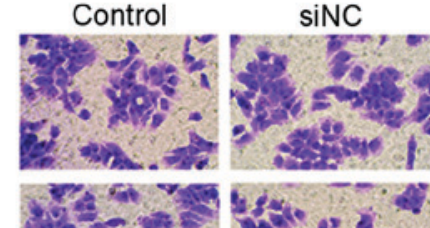

Rg3 (2.5)

$\operatorname{Rg} 3(5.0)$
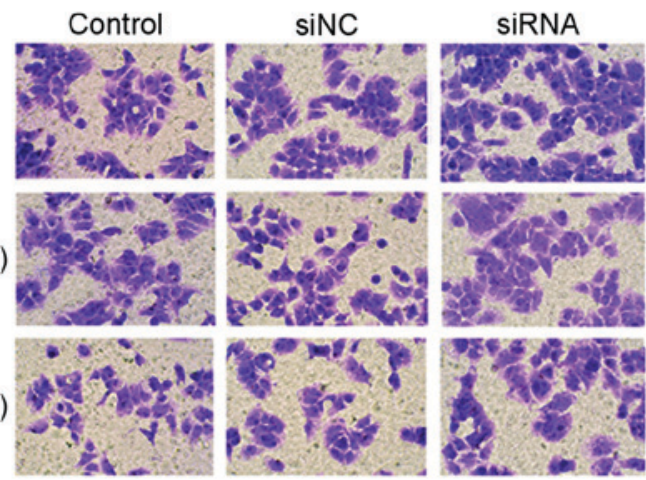

C

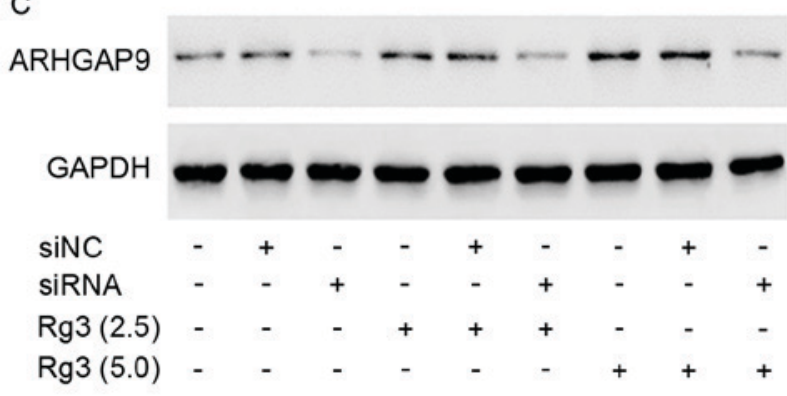

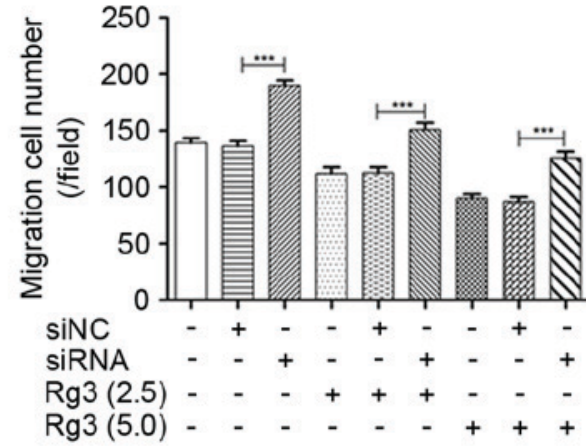
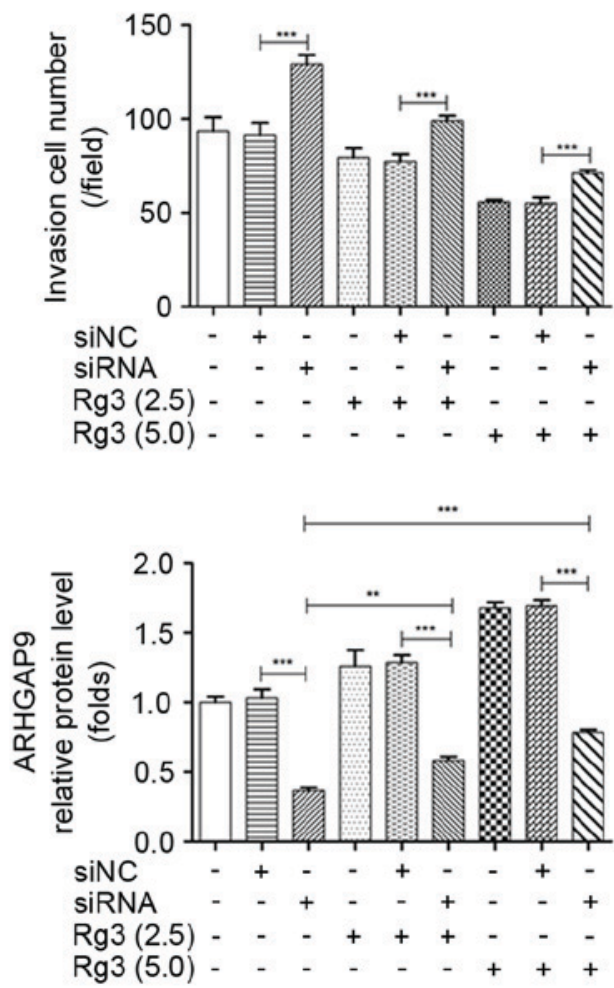

Figure 6. Knockdown of ARHGAP9 attenuates the anti-metastatic effect of Rg3 in MHCC-97L cells. Cells were transfected with siRNA against ARHGAP9 or siNC, and treated with 2.5 and $5 \mu \mathrm{g} / \mathrm{ml} \mathrm{Rg} 3$ or DMSO for $24 \mathrm{~h}$. Transwell assays were performed to evaluate (A) cell migration and (B) invasion. ${ }^{* * *} \mathrm{P}<0.001$, siRNA vs. siNC; siRNA $+2.5 \mu \mathrm{g} / \mathrm{ml}$ vs. siNC $+2.5 \mu \mathrm{g} / \mathrm{ml}$; siRNA $+5 \mu \mathrm{g} / \mathrm{ml}$ vs. siNC $+5 \mu \mathrm{g} / \mathrm{ml}$. (C) ARHGAP9 protein expression was measured by western blotting. ${ }^{* *} \mathrm{P}<0.01$, siRNA vs. siRNA+2.5 $\mu \mathrm{g} / \mathrm{ml}$; ${ }^{* * *} \mathrm{P}<0.001$, siRNA vs. siNC; siRNA+2.5 $\mu \mathrm{g} / \mathrm{ml}$ vs. siNC+2.5 $\mu \mathrm{g} / \mathrm{ml} ;$ siRNA+5 $\mu \mathrm{g} / \mathrm{ml}$ vs. siNC+5 $\mu \mathrm{g} / \mathrm{ml}$; siRNA vs. siRNA+5 $\mu \mathrm{g} / \mathrm{ml}$. si, small interfering RNA; NC, negative control; DMSO, dimethyl sulphoxide.

MHCC-97L cells to knockdown ARHGAP9. As demonstrated in Fig. 5C and D, all three siRNAs efficiently reduced the expression of ARHGAP9, among which siRNA3 was the most efficient, and selected for further experiments.

The essential aspects of ARHGAP9 function in cell metastasis with or without $\mathrm{Rg} 3$ treatment were explored by Transwell assays. It was demonstrated that the transfection of siRNA3 targeting ARHGAP9 significantly increased the migration and invasion rates of MHCC-97L cells, and attenuated the inhibition of cell migration and invasion induced by $\mathrm{Rg} 3$ (Fig. 6A and B). The increased expression of ARHGAP9 induced by Rg3 was markedly suppressed by the transfection of siRNA3 targeting ARHGAP9 compared with the siNC (Fig. 6C). In vivo, following treatment with $\mathrm{Rg} 3$ for 21 days, the siRNA3 targeting ARHGAP9 (siRNA) group tumors were larger than those in the siNC group (Fig. 7A). Compared with siNC+10 mg/kg Rg3 group, a significant increase in tumor weight was observed in the siRNA+10 mg/kg Rg3 group (Fig. 7B), and the average tumor diameters are listed in Table I. No BALB/c nude mice presented multiple tumors. The anti-metastasis experiments in vivo will be the next stage of our work. These results suggest that ARHGAP9 serves a key role in the metastasis-suppressive function of $\operatorname{Rg} 3$ in liver cancer.

\section{Discussion}

In the present study, it was demonstrated that $\mathrm{Rg} 3$ significantly reduces the migration and invasion capacity of liver cancer cells. The increased ARHGAP9 expression induced by Rg3 contributes to the anti-migration and anti-invasion effects of $\mathrm{Rg} 3$. The results revealed novel insight into the biological function of ARHGAP9 and suggest clinical application of $\operatorname{Rg} 3$ in liver cancer. 

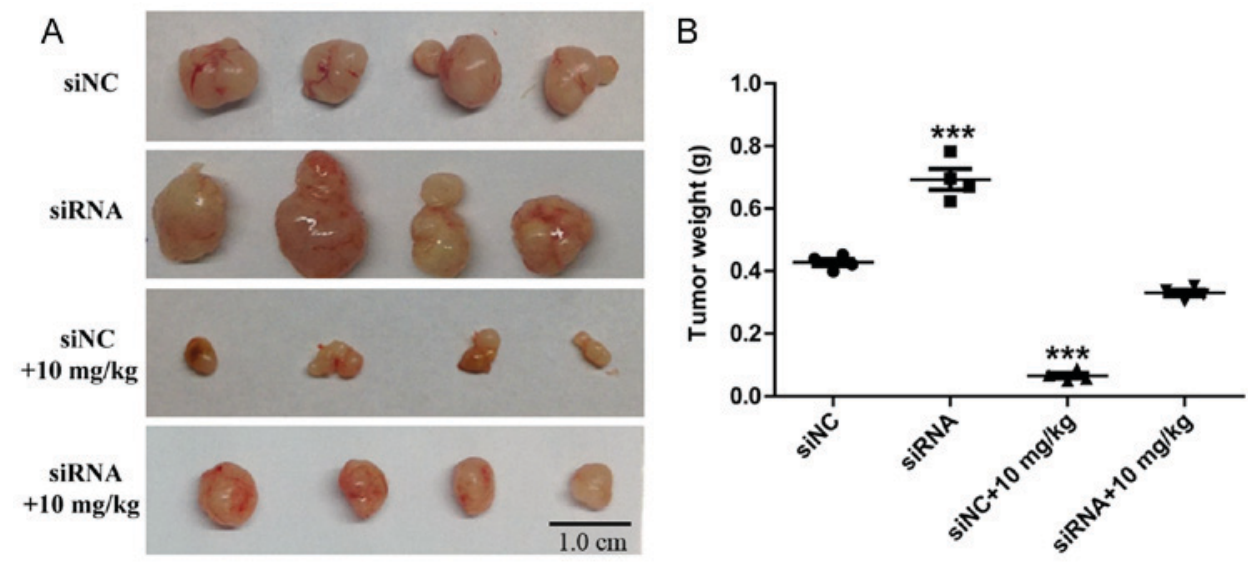

Figure 7. Knockdown of ARHGAP9 attenuates the anti-tumor growth effect of Rg3 in nude mice inoculated with MHCC-97L cells. (A) Photographs of MHCC-97L tumors (scale bars, $1 \mathrm{~cm}$ ). (B) Weight of MHCC-97L tumors. MHCC-97L cells transfected with siRNA-NC or siRNA3 were subcutaneously injected in the right forelimb of nude mice. $\mathrm{Rg} 3(10 \mathrm{mg} / \mathrm{kg})$ was administrated to the nude mice by gavage, and distilled water was used as a control. After 21 days the nude mice were sacrificed and tumor tissues were excised and weighed. $(\mathrm{n}=4)^{* * * * *} \mathrm{P}<0.001$ vs. siNC. si, small interfering RNA; NC, negative control.

Ginseng, the root of Panax ginseng C.A. Meyer, has been widely used in East Asian countries for thousands years as a natural tonic (30). The triterpene glycosides known as ginsenosides serve key roles in numerous medicinal effects of ginseng (31). Over 100 ginsenosides have been isolated from ginseng (32). Among these ginsenosides, ginsenoside Rg3, rich in red ginseng, has been demonstrated to be relatively safe medicinally, with significant anticancer activity in cancer models both in vitro and in vivo (33).

Despite liver cancer therapy, metastasis remains a clincial challenge (34). In recent years, Shenyi capsule (ginsenoside Rg3 monomer preparation) was approved by the China Food and Drug Administration for cancer therapy (35). Aside from its significant anti-cancer effects (36-38), $\operatorname{Rg} 3$ is a beneficial adjuvant to conventional cancer therapies due to its capacity to improve chemosensitivity, reduce adverse effects and enhance the immunity of tumor-bearing models (39-41). In the present study, the impact of $\operatorname{Rg} 3$ on liver cancer cell survival, migration and invasion, and growth of tumors in nude mice were explored. The results of cell viability and Transwell assays indicated that low concentrations $(1.25,2.5,5 \mu \mathrm{g} / \mathrm{ml})$ of $\mathrm{Rg} 3$ had no effect on the viability of HepG2 or MHCC-97L cells, but significantly inhibited the migration and invasion of tumor cells. Thus, $\operatorname{Rg} 3$ is a potential anti-metastatic agent for liver cancer. Combined administration of low-concentration $\operatorname{Rg} 3$ and conventional cancer therapies may have efficacy due to synergistic effects.

To further investigate the mechanism of $\operatorname{Rg} 3$ in liver cancer, the expression of ARHGAP9 protein was measured in vitro. It was demonstrated that $\mathrm{Rg} 3$ significantly upregulated ARHGAP9 expression in a dose-dependent manner. It was also confirmed that siRNA targeting ARHGAP9 transfection markedly reduced ARHGAP9 expression at the protein level, increased the migration and invasion rates of MHCC-97L cells, and attenuated the anti-migration and anti-invasive effects of Rg3. These findings suggest that Rg3 suppressed the migration and invasion of liver cancer cells by upregulating the expression of ARHGAP9.

ARHGAP9 belongs to the Rho GAPase family, which regulate cell migration in cancer progression by promoting
GTP hydrolysis to inactivate small GTPases through various downstream signaling pathways (42). Numerous GAPs have implicated in various types of cancer, including the tumor suppressor, DLC1, also known as ARHGAP7, which encodes Rho-GAP deleted frequently as p53 in liver, breast and lung cancer (43). Bioinformatics studies have confirmed that ARHGAP family genes (including ARHGAP9) are cancer-associated genes, as their genetic alterations are associated with carcinogenesis $(23,44)$. RhoGAP6 isoform 1 variant was identified as a biomarker for the development and progression of CRC (45). ARHGAP6 exerts a tumor-suppressive function via binding to Rac3, and may serve as a potential biomarker in cervical cancer (46). ARHGAP10 expression was downregulated in ovarian tumors and ARHGAP10 has been indicated to ameliorate ovarian cancer by inhibiting $\mathrm{Cdc} 42$ activation (47). Additionally, ARHGAP24 is implicated in breast cancer cell invasion and migration, RCC development and malignant lymphoma prognosis (48-50). Although ARHGAP9 has been associated with cancer in bioinformatics studies, no experiments have validated the association between ARHGAP9 and cancer. In the present study, it was demonstrated that ARHGAP9 exerted suppressive function in HCC migration and invasion, consistent with previous studies suggesting that RhoGAPs are tumor suppressors $(43,49)$. However, the exact mechanism by which ARHGAP9 exerts its function remains to be further investigated.

It is notable that, although GAPs have been increasingly reported to be involved in major aspects of cancer development, the mechanism of GAP regulation and alterations by GAPs in different types of cancer remains unknown. It has been suggested that the association of RhoGAPs with cancer could be mediated by the Rho pathway and Rho-independent pathways. A number of RhoGAPs have been reported to directly bind to p53 tumor suppressor protein, and regulate the cell cycle and apoptosis (51). RhoGAPs may serve as a key crossroad between the cell-migration and proliferation pathways. Thus, an improved understanding of the molecular mechanisms of ARHGAP9 underlying the carcinogenesis of liver cancer is required, which may allow the development of novel therapeutic strategies. 
Table I. Tumor diameter measurements.

Average diameter of tumor $(\mathrm{cm})$

\begin{tabular}{|c|c|c|c|c|}
\hline \multirow[b]{2}{*}{ Time (day) } & \\
\hline & siNC & siRNA & $\mathrm{siNC}+10 \mathrm{mg} / \mathrm{kg}$ & $\mathrm{siRNA}+10 \mathrm{mg} / \mathrm{kg}$ \\
\hline 9 & $0.34 \pm 0.06$ & $0.42 \pm 0.06$ & $0.08 \pm 0.01^{\mathrm{a}, \mathrm{b}}$ & $0.22 \pm 0.04^{\mathrm{b}}$ \\
\hline 12 & $0.57 \pm 0.05$ & $0.73 \pm 0.08$ & $0.12 \pm 0.02^{\mathrm{a}, \mathrm{b}}$ & $0.34 \pm 0.05^{\mathrm{b}}$ \\
\hline 15 & $0.77 \pm 0.07$ & $0.96 \pm 0.09^{\mathrm{a}}$ & $0.21 \pm 0.04^{\mathrm{a}, \mathrm{b}}$ & $0.47 \pm 0.07^{b}$ \\
\hline 18 & $0.90 \pm 0.08$ & $1.29 \pm 0.10^{\mathrm{a}}$ & $0.30 \pm 0.05^{\mathrm{a}, \mathrm{b}}$ & $0.53 \pm 0.09^{b}$ \\
\hline 21 & $1.02 \pm 0.11$ & $1.65 \pm 0.14^{\mathrm{a}}$ & $0.39 \pm 0.05^{\mathrm{a}}$ & $0.62 \pm 0.12^{\mathrm{b}}$ \\
\hline
\end{tabular}

${ }^{\mathrm{a}} \mathrm{P}<0.05$ vs. siNC; ${ }^{\mathrm{b}} \mathrm{P}<0.05$ vs. siRNA; si, small interfering RNA; NC, negative control.

In summary, the present study indicated that ARHGAP9 may serve an important role in the metastasis of liver cancer, and that $\operatorname{Rg} 3$ inhibited the migration and invasion of liver cancer by upregulating the expression of ARHGAP9. ARHGAP9 may provide a novel strategy for treating liver cancer. The signaling pathway of Rg3-induced ARHGAP9 and the association between ARHGAP9 expression and clinicopathological features of patients with liver cancer will be conducted to fully investigate these possibilities.

\section{Acknowledgements}

The authors would like to thank Dr Jianyong Zhu (Central Laboratory, Seventh People's Hospital of Shanghai University of Traditional Chinese Medicine, China) for providing writing advice and improving the present manuscript.

\section{Funding}

The present study was supported by funds from the National Natural Science Foundation of China (grant nos. 81502515, 81503332, 81703755 and 81773941), Outstanding Leaders Training Program of Pudong Health Bureau of Shanghai (grant no. PWR12015-05), Key Disciplines Group Construction Project of Pudong Health Bureau of Shanghai (grant no. PWZxq2014-12 and PWZx2014-17) and the Talents Training Program of Seventh People's Hospital of Shanghai University of TCM (grant no. XX2017-01).

\section{Availability of data and materials}

The datasets used and/or analysed during the current study are available from the corresponding author on reasonable request.

\section{Authors' contributions}

HZ and LJZ conceived and designed the study. MYS performed the experiments and collected data. YNS, MZ and CYZ performed the data analysis. All authors discussed and interpreted the data. MYS wrote the manuscript. All authors reviewed and edited the manuscript. All authors read and approved the final manuscript.

\section{Ethics approval and consent to participate}

The use of animals in the present study was approved by the Experimental Animal Ethical Committee of Seven People's Hospital, Shanghai University of Traditional Chinese Medicine.

\section{Patient consent for publication}

Not applicable.

\section{Competing interest}

The authors declare that they have no competing interests.

\section{References}

1. Torre LA, Bray F, Siegel RL, Ferlay J, Lortet-Tieulent J and Jemal A: Global cancer statistics, 2012. CA Cancer J Clin 65: 87-108, 2015.

2. Maluccio M and Covey A: Recent progress in understanding, diagnosing, and treating hepatocellular carcinoma. CA Cancer J Clin 62: 394-399, 2012.

3. Han W, Fu X, Xie J, Meng Z, Gu Y, Wang X, Li L, Pan H and Huang W: MiR-26a enhances autophagy to protect against ethanol-induced acute liver injury. J Mol Med 93: 1045-1055, 2015.

4. Palmer DH, Hussain SA, Smith AJ, Hargreaves S, Ma YT, Hull D, Johnson PJ and Ross PJ: Sorafenib for advanced hepatocellular carcinoma (HCC): Impact of rationing in the United Kingdom. Br J Cancer 109: 888-890, 2013.

5. Tanaka Y, Hanada K, Mizokami M, Yeo AE, Shih JW, Gojobori T and Alter HJ: A comparison of the molecular clock of hepatitis C virus in the United States and Japan predicts that hepatocellular carcinoma incidence in the United States will increase over the next two decades. Proc Natl Acad Sci USA 99: 15584-15589, 2002.

6. Forner A, Hessheimer AJ, Isabel Real M and Bruix J: Treatment of hepatocellular carcinoma. Crit Rev Oncol Hematol 60: 89-98, 2006.

7. Sherman M: Hepatocellular carcinoma: Epidemiology, risk factors, and screening, Seminars in liver disease. Semin Liver Dis 25: 143-154, 2005.

8. Althoff TF and Offermanns S: G-protein-mediated signaling in vascular smooth muscle cells-implications for vascular disease. J Mol Med 93: 973-981, 2015.

9. Huh YH, Oh S, Yeo YR, Chae IH, Kim SH, Lee JS, Yun SJ, Choi KY, Ryu JH and Jun CD: Swiprosin-1 stimulates cancer invasion and metastasis by increasing the Rho family of GTPase signaling. Oncotarget 6: 13060-13071, 2015.

10. Deryugina EI and Quigley JP: Matrix metalloproteinases and tumor metastasis. Cancer Metastasis Rev 25: 9-34, 2006. 
11. Chen CK, Yu WH, Cheng TY, Chen MW, Su CY, Yang YC, Kuo TC, Lin MT, Huang YC, Hsiao M, et al: Inhibition of VEGF165/VEGFR2-dependent signaling by LECT2 suppresses hepatocellular carcinoma angiogenesis. Sci Rep 6: 31398, 2016.

12. Lampelj M, Arko D, Cas-Sikosek N, Kavalar R, Ravnik M, Jezersek-Novakovic B, Dobnik S, Dovnik NF and Takac I: Urokinase plasminogen activator (uPA) and plasminogen activator inhibitor type-1 (PAI-1) in breast cancer - correlation with traditional prognostic factors. Radiol Oncol 49: 357-364, 2015.

13. Guo H, Xing Y, Mu A, Li X, Li T, Bian X, Yang C, Zhang X, Liu Y and Wang X: Correlations between EGFR gene polymorphisms and pleural metastasis of lung adenocarcinoma. Onco Targets Ther 9: 5257-5270, 2016.

14. Etienne-Manneville S and Hall A: Rho GTPases in cell biology. Nature 420: 629-635, 2002

15. Vega FM and Ridley AJ: Rho GTPases in cancer cell biology. FEBS Lett 582: 2093-2101, 2008.

16. Haga RB and Ridley AJ: Rho GTPases: Regulation and roles in cancer cell biology. Small GTPases 7: 207-221, 2016.

17. Wong CC, Wong CM, Au SL and Ng IO: RhoGTPases and Rho-effectors in hepatocellular carcinoma metastasis: ROCK N Rho move it. Liver Int 30: 642-656, 2010.

18. Grise F, Bidaud A and Moreau V: Rho GTPases in hepatocellular carcinoma. Biochim Biophys Acta 1795: 137-151, 2009.

19. Kandpal RP: Rho GTPase activating proteins in cancer phenotypes. Curr Protein Pept Sci 7: 355-365, 2006.

20. Furukawa Y, Kawasoe T, Daigo Y, Nishiwaki T, Ishiguro H, Takahashi M, Kitayama J and Nakamura Y: Isolation of a novel human gene, ARHGAP9, encoding a rho-GTPase activating protein. Biochem Biophys Res Commun 284: 643-649, 2001.

21. Ang BK, Lim CY, Koh SS, Sivakumar N, Taib S, Lim KB Ahmed S, Rajagopal G and Ong SH: ArhGAP9, a novel MAP kinase docking protein, inhibits Erk and p38 activation through WW domain binding. J Mol Signal 2: 1, 2007.

22. Takefuji M, Asano H, Mori K, Amano M, Kato K, Watanabe T, Morita Y, Katsumi A, Itoh T, Takenawa T, et al: Mutation of ARHGAP9 in patients with coronary spastic angina. J Hum Genet 55: 42-49, 2010

23. Katoh $\mathrm{M}$ and Katoh M: Identification and characterization of ARHGAP24 and ARHGAP25 genes in silico. Int J Mol Med 14: 333-338, 2004.

24. Kim YJ, Choi WI, Jeon BN, Choi KC, Kim K, Kim TJ, Ham J, Jang HJ, Kang KS and Ko H: Stereospecific effects of ginsenoside $20-\mathrm{Rg} 3$ inhibits TGF- $\beta 1$-induced epithelial-mesenchymal transition and suppresses lung cancer migration, invasion and anoikis resistance. Toxicology 322: 23-33, 2014.

25. Tian L, Shen D, Li X, Shan X, Wang X, Yan Q and Liu J: Ginsenoside Rg3 inhibits epithelial-mesenchymal transition (EMT) and invasion of lung cancer by down-regulating FUT4 Oncotarget 7: 1619-1632, 2016.

26. Junmin S, Hongxiang L, Zhen L, Chao Y and Chaojie W: Ginsenoside Rg3 inhibits colon cancer cell migration by suppressing nuclear factor kappa B activity. J Tradit Chin Med 35: 440-444, 2015

27. Xu TM, Cui MH, Xin Y, Gu LP, Jiang X, Su MM, Wang DD and Wang WJ: Inhibitory effect of ginsenoside Rg3 on ovarian cancer metastasis. Chin Med J (Engl) 121: 1394-1397, 2008.

28. Chen QJ, Zhang MZ and Wang LX: Gensenoside Rg3 inhibits hypoxia-induced VEGF expression in human cancer cells. Cell Physiol Biochem 26: 849-858, 2011.

29. Lee YS, Kang YS, Lee SH and Kim JA: Role of NAD(P)H oxidase in the tamoxifen-induced generation of reactive oxygen species and apoptosis in HepG2 human hepatoblastoma cells. Cell Death Differ 7: 925-932, 2000.

30. Zhang QH, Wu CF, Duan L and Yang JY: Protective effects of ginsenoside $\operatorname{Rg}(3)$ against cyclosphosphamide-induced DNA damage and cell apoptosisin mice. Arch Toxicol 82:117-123, 2008

31. Kim JH: Pharmacological and medical applications of Panax ginseng and ginsenosides: A review for use in cardiovascular diseases. J Ginseng Res 42: 264-269, 2018.

32. Lü JM, Yao Q and Chen C: Ginseng compounds: An update on their molecular mechanisms and medical applications. Curr Vasc Pharmacol 7: 293-302, 2009.

33. Huang JY, Sun Y, Fan QX and Zhang YQ: Efficacy of Shenyi Capsule combined with gemcitabine plus cisplatin in treatment of advanced esophageal cancer: A randomized controlled trial. Zhong Xi Yi Jie He Xue Bao 7: 1047-1051, 2009 (In Chinese).
34. Forner A, Llovet JM and Bruix J: Hepatocellularcarcinoma. Lancet 379: 1245-1255, 2012.

35. Sun Y, Lin H, Zhu Y, Feng J, Chen Z, Li G, Zhang X, Zhang Z, Tang J, Shi M, Hao X and Han H: A randomized, prospective, multi-centre clinical trial of NP regimen (vinorelbine+cisplatin) plus Gensing $\operatorname{Rg} 3$ in the treatment of advanced non-small cell lung cancer patients. Zhongguo Fei Ai Za Zhi 9: 254-258, 2006 (In Chinese).

36. Jiang JW, Chen XM, Chen XH and Zheng SS: Ginsenoside Rg3 inhibit hepatocellular carcinoma growth via intrinsic apoptotic pathway. World J Gastroenterol 17: 3605-3613, 2011.

37. Shan X, Aziz F, Tian LL, Wang XQ, Yan Q and Liu JW: Ginsenoside Rg3-induced EGFR/MAPK pathway deactivation inhibits melanoma cell proliferation by decreasing FUT4/LeY expression. Int J Oncol 46: 1667-1676, 2015.

38. Shan X, Fu YS, Aziz F, Wang XQ, Yan Q and Liu JW Ginsenoside Rg3 inhibits melanoma cell proliferation through down-regulation of histone deacetylase 3 (HDAC3) and increase of p53 acetylation. PLoS One 9: e115401, 2014

39. Kim SM, Lee SY, Cho JS, Son SM, Choi SS, Yun YP, Yoo HS, Yoon DY, Oh KW, Han SB and Hong JT: Combination of ginsenoside $\mathrm{Rg} 3$ with docetaxel enhances the susceptibility of prostate cancer cells via inhibition of NF-kappaB. Eur J Pharmacol 631: 1-9, 2010

40. Wang X, Chen L, Wang T, Jiang X, Zhang H, Li P, Lv B and Gao X: Ginsenoside Rg3 antagonizes adriamycin-induced cardiotoxicity by improving endothelial dysfunction from oxidative stress via upregulating the Nrf2-ARE pathway through the activation of akt. Phytomedicine 22: 875-884, 2015.

41. Park D, Bae DK, Jeon JH, Lee J, Oh N, Yang G, Yang YH, Kim TK, Song J, Lee SH, et al: Immunopotentiation and antitumor effects of a ginsenoside $\operatorname{Rg}(3)$-fortified red ginseng preparation in mice bearing H460 lung cancer cells. Environ Toxicol Pharmacol 31: 397-405, 2011.

42. Amin E, Jaiswal M, Derewenda U, Reis K, Nouri K, Koessmeier KT, Aspenström P, Somlyo AV, Dvorsky R and Ahmadian MR: Deciphering the molecular and functional Basis of RHOGAP family proteins A systematic approach toward selective inactivation of rho family proteINS. J Biol Chem 291: 20353-20371, 2016.

43. Tripathi BK, Qian X, Mertins P, Wang D, Papageorge AG, Carr SA and Lowy DR: CDK5 is a major regulator of the tumor suppressor DLC1. J Cell Biol 207: 627-642, 2014.

44. Katoh Y and Katoh M: Identification and characterization of ARHGAP27 gene in silico. Int J Mol Med 14: 943-947, 2004.

45. Guo F, Liu Y, Huang J, Li Y, Zhou G, Wang D, Li Y, Wang J, Xie P and Li G: Identification of Rho GTPase activating protein 6 isoform 1 variant as a new molecular marker in human colorectal tumors. Pathol Oncol Res 16: 319-326, 2010.

46. Li J, Liu Y and Yin Y: Inhibitory effects of Arhgap6 on cervical carcinoma cells. Tumour Biol 37: 1411-1425, 2016.

47. Luo N, Guo J, Chen L, Yang W, Qu X and Cheng Z: ARHGAP10, downregulated in ovarian cancer, suppresses tumorigenicity of ovarian cancer cells Cell Death Dis 7: e2157, 2016.

48. Saito K, Ozawa Y, Hibino K and Ohta Y: FilGAP, a Rho/Rho-associated protein kinase-regulated GTPase-activating protein for Rac, controls tumor cell migration. Mol Biol Cell 23: 4739-4750, 2012

49. Xu G, Lu X, Huang T and Fan J: ARHGAP24 inhibits cell cycle progression, induces apoptosis and suppresses invasion in renal cell carcinoma. Oncotarget 7: 51829-51839, 2016.

50. Nishi T, Takahashi H, Hashimura M, Yoshida T, Ohta Y and Saegusa M: FilGAP, a Rac-specific Rho GTPase-activating protein, is a novel prognostic factor for follicular lymphoma. Cancer Med 4: 808-818, 2015.

51. Xu J, Zhou X, Wang J, Li Z, Kong X, Qian J, Hu Y and Fang JY: RhoGAPs attenuate cell proliferation by direct interaction with p53 tetramerization domain. Cell Rep 3: 1526-1538, 2013.

This work is licensed under a Creative Commons Attribution-NonCommercial-NoDerivatives 4.0 International (CC BY-NC-ND 4.0) License. 